\title{
Mineral composite assessment of Kelkit River Basin in Turkey by means of remote sensing
}

\author{
HAKAN Mete Dogan \\ Faculty of Agriculture, Department of Soil Science, GIS\&RS Unit, Gaziosmanpaşa University, \\ Tasliciftlik 60240, Tokat/Turkey. \\ e-mail: hmdogan@hotmail.com
}

\begin{abstract}
Utilizing remote sensing (RS) and geographic information systems (GIS) tools, mineral composite characteristics (ferrous minerals (FM), iron oxide (IO), and clay minerals (CM)) of the Kelkit River Basin $\left(15913.07 \mathrm{~km}^{2}\right)$ in Turkey were investigated and mapped. Mineral composite (MC) index maps were produced from three LANDSAT-ETM+ satellite images taken in 2000. Resulting MC index maps were summarized in nine classes by using 'natural breaks' classification method in GIS. Employing bi-variety correlation analysis, relationships among index maps were investigated. According to the results, FM and IO index maps showed positive correlation, while CM index map is negatively correlated with FM and IO index maps. Negative correlations between iron and clay variables suggested that the dominant clay minerals of the study area might be smectite, illite, kaolinite, and chlorite, which have little or no iron content. Using field data for which their geographic coordinates had been determined by global positioning system (GPS), developed MC maps were verified, and found dependable for environmental and ecological modeling studies.
\end{abstract}

\section{Introduction}

Clay minerals (CM) consisting of a group of hydrous aluminium silicates (phyllosilicates or layer silicates less than $2 \mu \mathrm{m}$ in diameter) are important for agriculture (Moore and Reynolds 1977; Murray 2006). Kaolinite, illite, vermiculite, montmorillonite-smectite and chlorite are the five major types of CM (Sposito 1989), and play a very important role in the chemical reaction in soil by influencing the movement and retention of contaminants, metals, and nutrients (Grim 1962). CM can hold moisture and plant nutrient elements effectively (Akalan 1977). Therefore, a certain amount of clay in all soils is necessary for all plants and productive agriculture. Not only clay but also iron is an important element that has been found in augite, biotite, hematite, hornblende, goethite, lepidocrocite, limonite, magnetite, and olivine minerals (Bolt and Bruggenwert
1976; Durak et al 2003). Iron is important for human and plant health. It has a crucial role for chlorophyll synthesis and growth (Gris 1844). Iron deficiency induces chlorosis which is represented by yellow leaves with green veins and poor fruits in plants (Somers and Shive 1942; Brown 1956; Haktanır and Arcak 1997; Atalay 2006). Two important indicators of iron are known as ferrous minerals (FM) and iron oxide (IO). In remote sensing (RS), the term of mineral composite (MC) has been used to express a group of minerals that consists of CM, FM and IO. Determining spatial distribution of $\mathrm{MC}$ is important for some environmental and ecological modelling studies, and geographic information systems (GIS) and RS are important techniques for modelling. Using these powerful tools, many applications including ferric oxide-oxyhydroxide minerals (Farrand 1997), metamorphic rocks (Longhi et al 2001), mineral exploration (Akhavi et al 2001; Neville et al 2003),

Keywords. Remote sensing; image analysis; mineral composite; GIS; LANDSAT; mineralogy and petrology. 


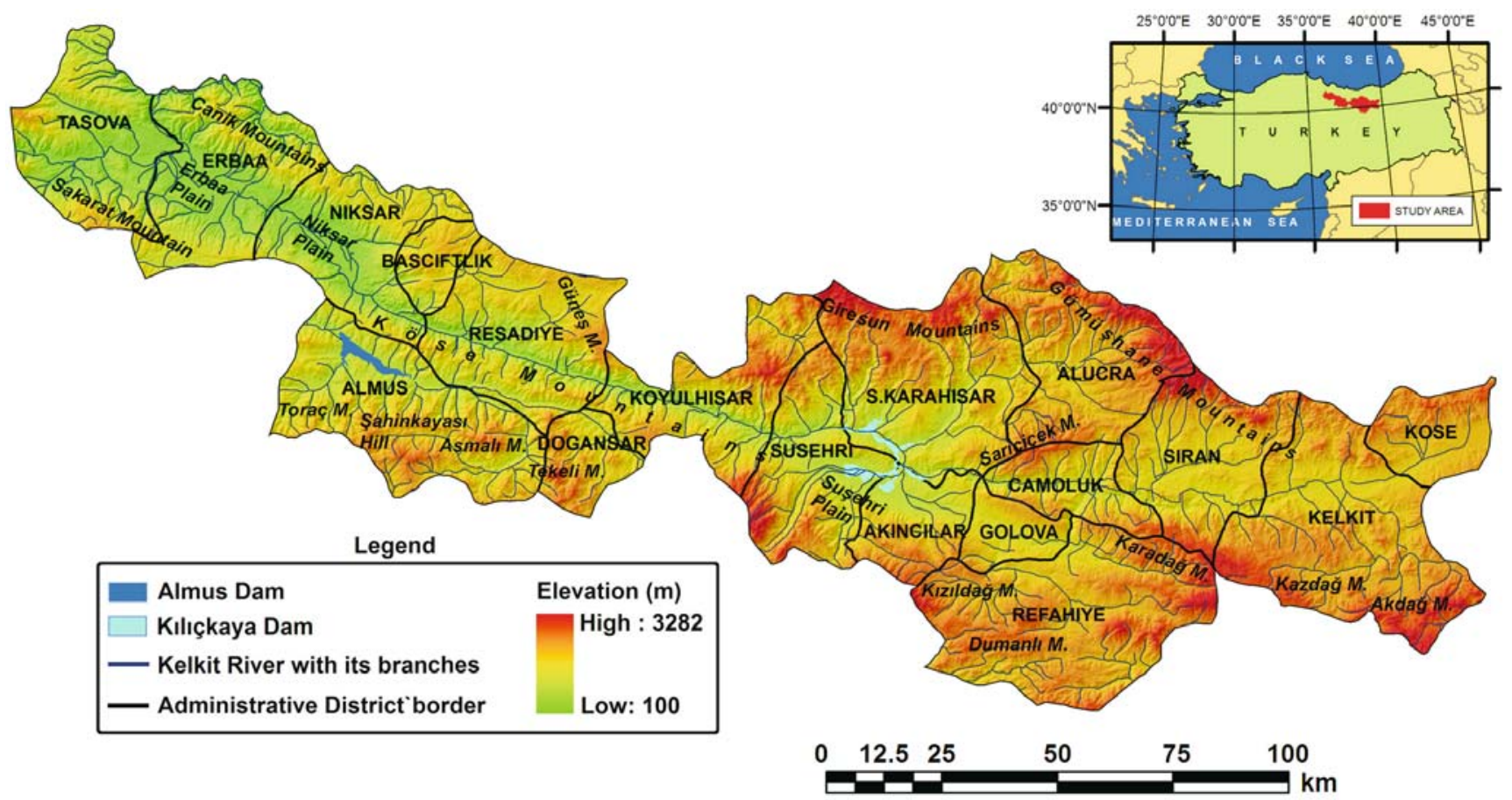

Figure 1. Geographic location, physical geography and administrative districts of the study area.

Table 1. Algorithms of employed indices and band information of LANDSAT-ETM+ (Tucker 1979; Sabins 1987; Jensen 1996; Campbell 1996; ERDAS 2003; USGS 2006).

\begin{tabular}{lll}
\hline Indices & & Algorithms \\
\hline Mineral composite & $\begin{array}{l}\text { Ferrous minerals } \\
\text { Iron oxide }\end{array}$ & $\begin{array}{l}\text { band } 5 / \text { band } 4 \\
\text { band } 3 / \text { band } 1\end{array}$ \\
& Clay minerals & band $5 /$ band 7 \\
Normalized difference vegetative (NDVI) & (band $4-$ band 3)/(band $4+$ band 3) \\
Band & Wavelength $(\mu \mathbf{m})$ & Spectrum \\
\hline Band 1 & $0.450-0.515$ & Visible (Blue) \\
Band 3 & $0.630-0.690$ & Visible (Red) \\
Band 4 & $0.750-0.900$ & Near Infrared \\
Band 5 & $1.550-1.750$ & Mid Infrared \\
Band 7 & $2.09-2.35$ & Mid Infrared \\
\hline
\end{tabular}

porphyry copper alteration (Tangestani and Moore 2002), primary granite and its subsequent kaolinisation (Ellis and Scott 2004), and crystalline ferric and FM (Sabol et al 1993) were done successfully in the past.

The Kelkit Basin is located in a region having importance in both agriculture and bio-diversity. Despite of its importance, this is one of the least studied areas in Turkey. Updated thematic maps that contain detailed geographic information are extremely important for the area to establish a good basis for a healthy economical development. On the other hand, existing geographic information about natural resources of the region do not have enough capacity to fulfill these requirements. This study has been aimed to develop updated thematic maps that reveal the spatial distribution of MC of the Kelkit Basin. The produced maps have the potential to help the decision makers and researchers who study in the region, and can be useful for the studies devoted to agriculture, environment, and ecology.

\section{Study area}

Main part of the Kelkit Basin is located in the transition zone between the Middle Black Sea and Inner Anatolia regions (figure 1). The study area covers $15913.07 \mathrm{~km}^{2}$ including 18 administrative districts 


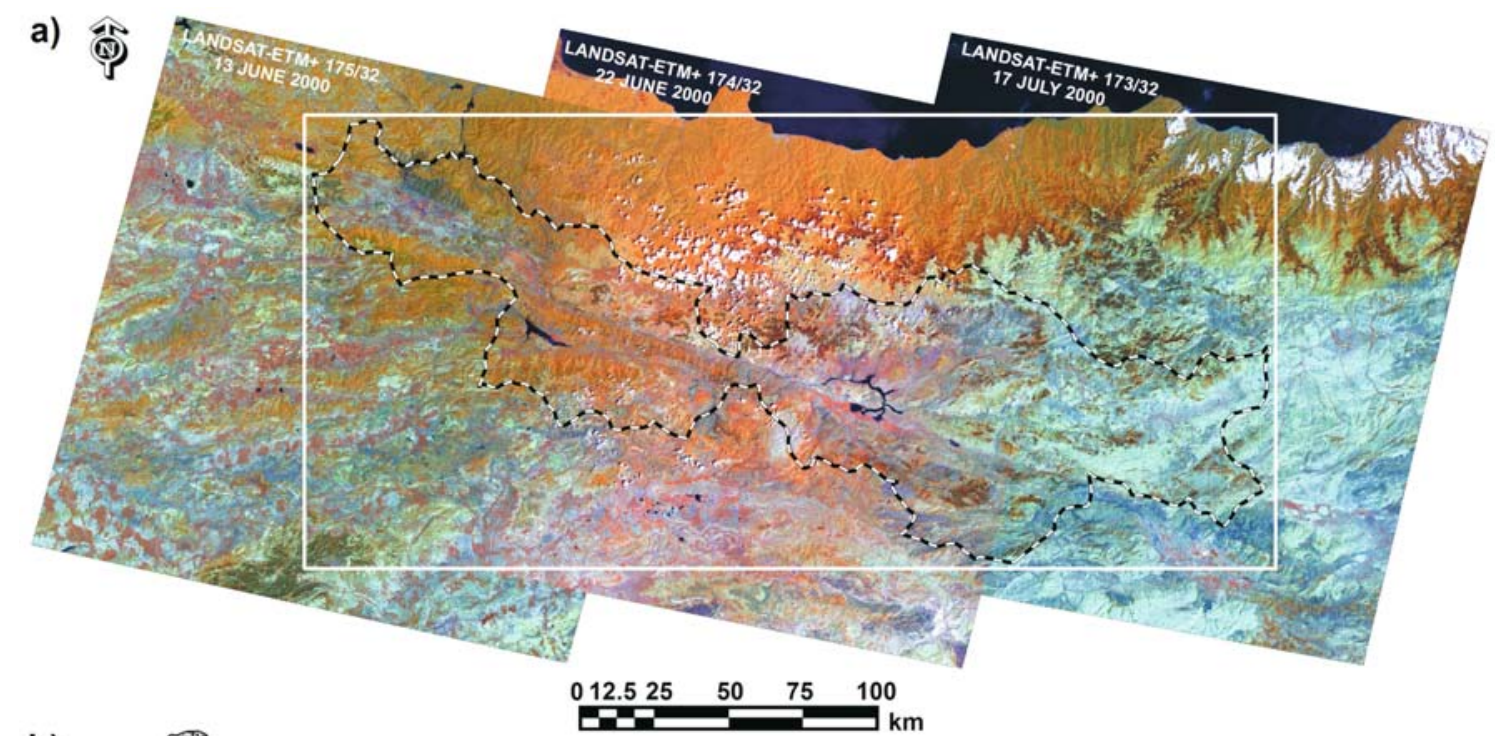

b)

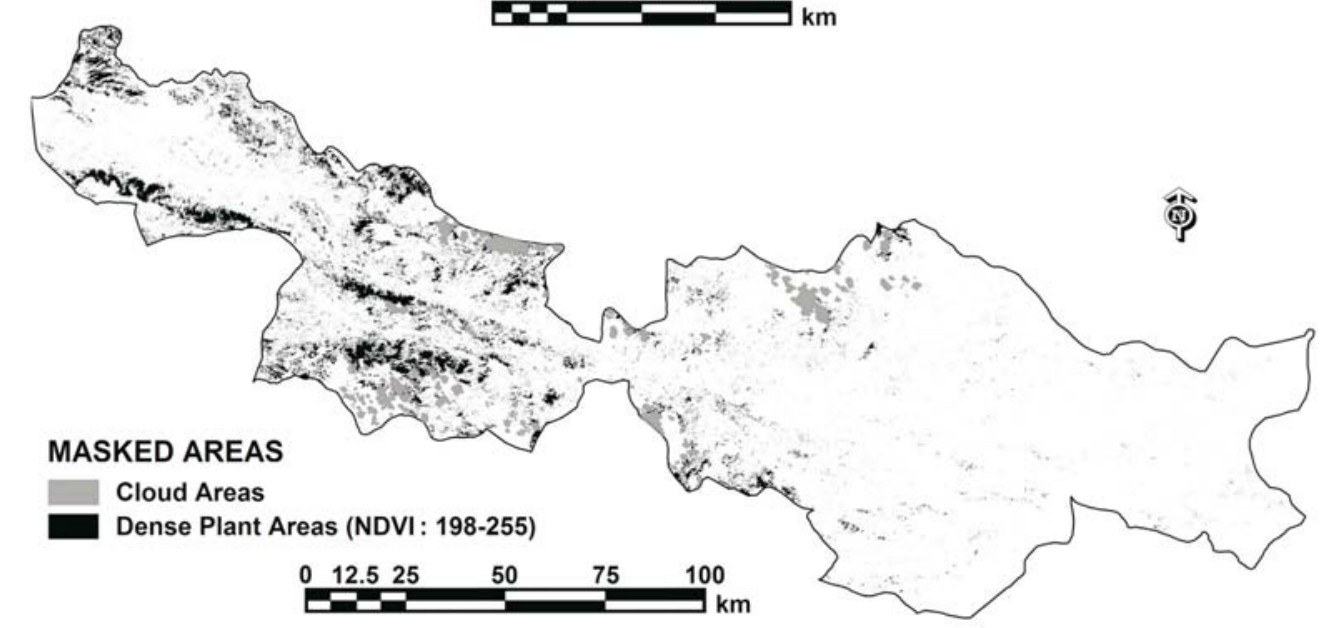

Figure 2. Mosaic LANDSAT-ETM+ image and AOI layer of the study area (a) and masking (cloud and dense plant) areas excluded from evaluation (b).

of six different provinces (Taşova, Refahiye, S. Karahisar, Alucra, Camoluk, Siran, Kose, Kelkit, Koyulhisar, Susehri, Doğansar, Akincilar, Golova, Almus, Erbaa, Niksar, Basciftlik, Resadiye). Four seasons (autumn, winter, spring, and summer) are recognized in this region. The climate of the study area shows 'Semi-arid Upper Mediterranean Bio climate' characteristics with cold winters (Akman and Daget 1971; Akman 1999).

The topography of the area is rugged with elevation ranging from 100 to $3282 \mathrm{~m}$ (figure 1). Elevation increases from west to east. Erbaa, Niksar, and Suşehri plains are the main areas where agricultural activities are important. Thirteen great soil groups recognized in the area can be summarized as brown forest (46.54\%), noncalcerous brown forest (14.08\%), brown (12.60\%), chestnut $(6.08 \%)$, stony-rocky areas $(5.63 \%)$, noncalcerous brown $(4.56 \%)$, high mountain-rangeland (3.51\%), alluvial $(2.85 \%)$, colluvial $(2.34 \%)$, reddish brown $(1.10 \%)$, grey brown podsolic $(0.63 \%)$, hydromorphic $(0.06 \%)$, and salty-alkaline $(0.03)$ (KHGM 2002). Quartz, feldspar, biotite, trace amounts of augite together with pumice and volcanic rock fragments are the volcanogenic components of the region, while diagenetic minerals are represented by clay, calcite, opal-CT, zeolite and dolomite (Yalcin and Gumuser 2000).

\section{Methodology}

The methodology has been based on the mineral composite (FM, IO, and CM) and normalized difference vegetative (NDVI) indices (Tucker 1979; Sabins 1987; Jensen 1996; Campbell 1996; ERDAS 2003). The role of NDVI was to mask dense plant areas. All these indices were calculated by utilizing LANDSAT Enhanced Thematic Mapper Plus $(\mathrm{ETM}+)$ (spatial resolution: $30 \mathrm{~m})$ satellite data (USGS 2006) and related algorithms (table 1). The ratios $3 / 1,5 / 7$, and $5 / 4$ of component technique 

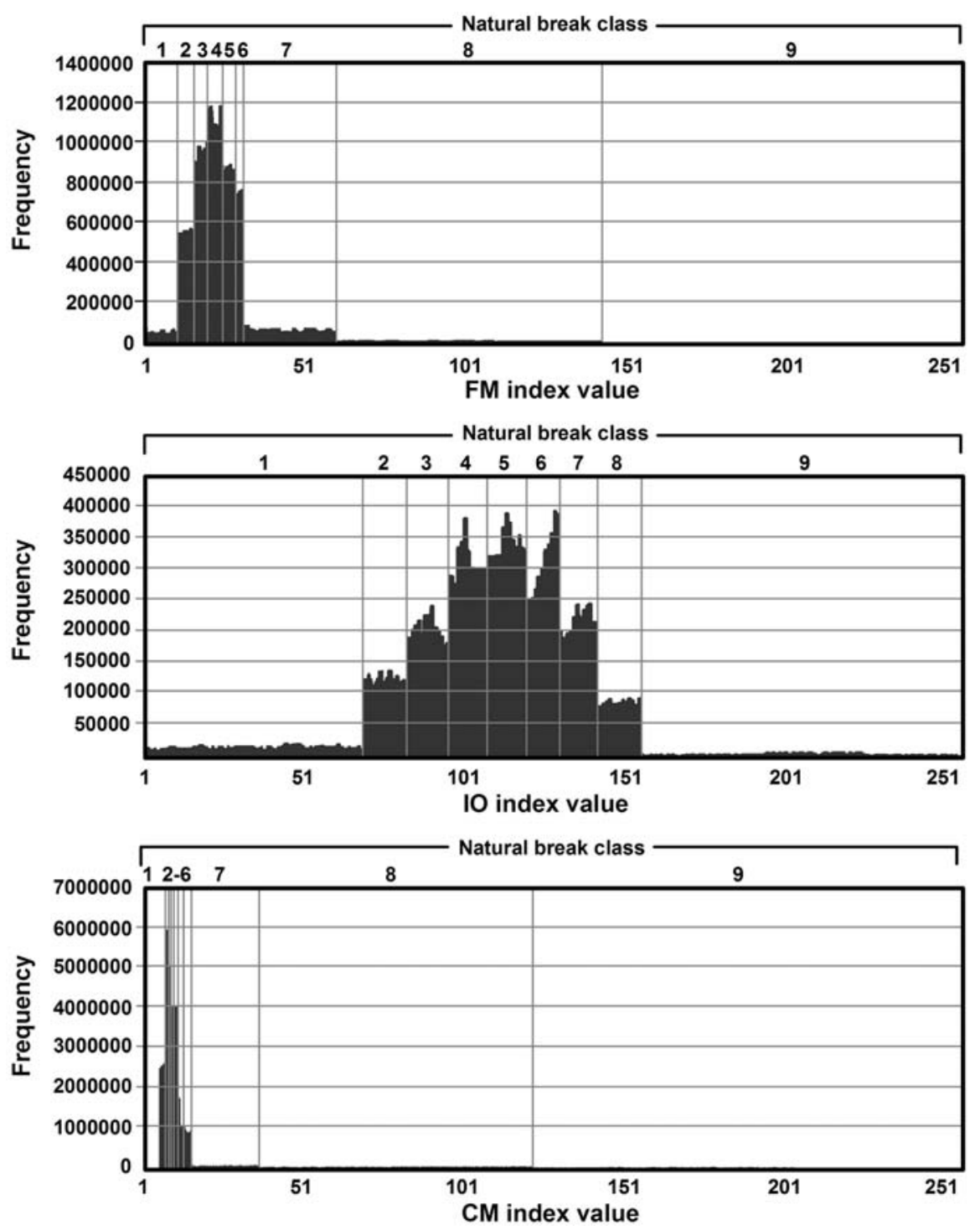

Figure 3. Histograms of ferrous minerals, iron oxide, and clay minerals index maps.

were selected for their sensitivity to lithologic variables and for their lack of statistical redundancy. Prior the calculation of all indices, three LANDSAT-ETM+ images - detected on 13 June, 22 June, and 17 July 2000 (path/row: 175/32, $174 / 32$, and $173 / 32$ ) - were downloaded free from the website of Michigan State University in TIFF format (www.landsat.org, accessed on 8 July 2006). Downloaded bands $(1,3,5,7)$ of each image were used to create false colour composite (FCC) maps using ERDAS-Imagine (version 8.7) software (ERDAS 2003). Although all downloaded image files have ortho-geocover attributes, their geometric corrections were tested by using 37 ground control points, and found accurate (root mean square $(\mathrm{RMS})$ error $<0.001)$ enough to proceed. Mosaicing of the three FCCs covering the study area was done using overlay function of ERDAS-Imagine (figure 2A). The mosaic image was subset to obtain the area of interest (AOI) by using a vector AOI that was created from the map of Kelkit provinces (figure 2A). Then, a radiometric enhancement was applied on the subset mosaic image to remove effects of haze using image interpreter tool of ERDAS-Imagine. Cloudy areas on the subset mosaic image were converted to a shape file in ARCGIS software (ESRI 2004, 2005). Moreover, closed forest or dense plant covers (UNESCO 1973) were determined by using NDVI values between 198 and 255, and converted to a shape file in ARCGIS. Both cloudy and dense plant areas were unified to establish a masking shape file (figure 2B), and excluded from the subset mosaic image. Then, this masked subset mosaic image was used to create index maps of FM, IO, and CM by using spectral enhancement technique in ERDAS-Imagine in order to bring out hidden and unclear land features. Using $5 \times 5$ windows, all 
a)
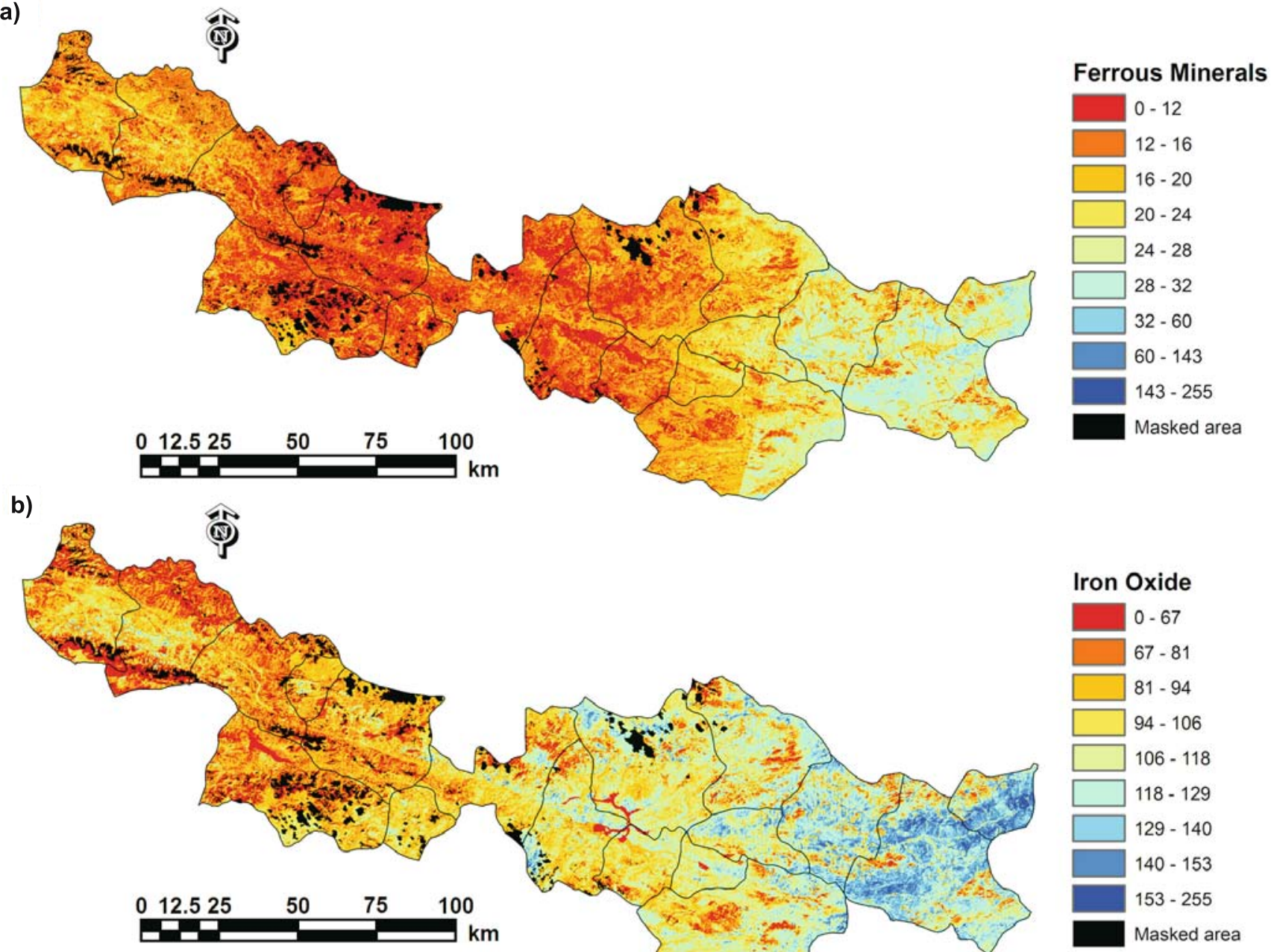

c)
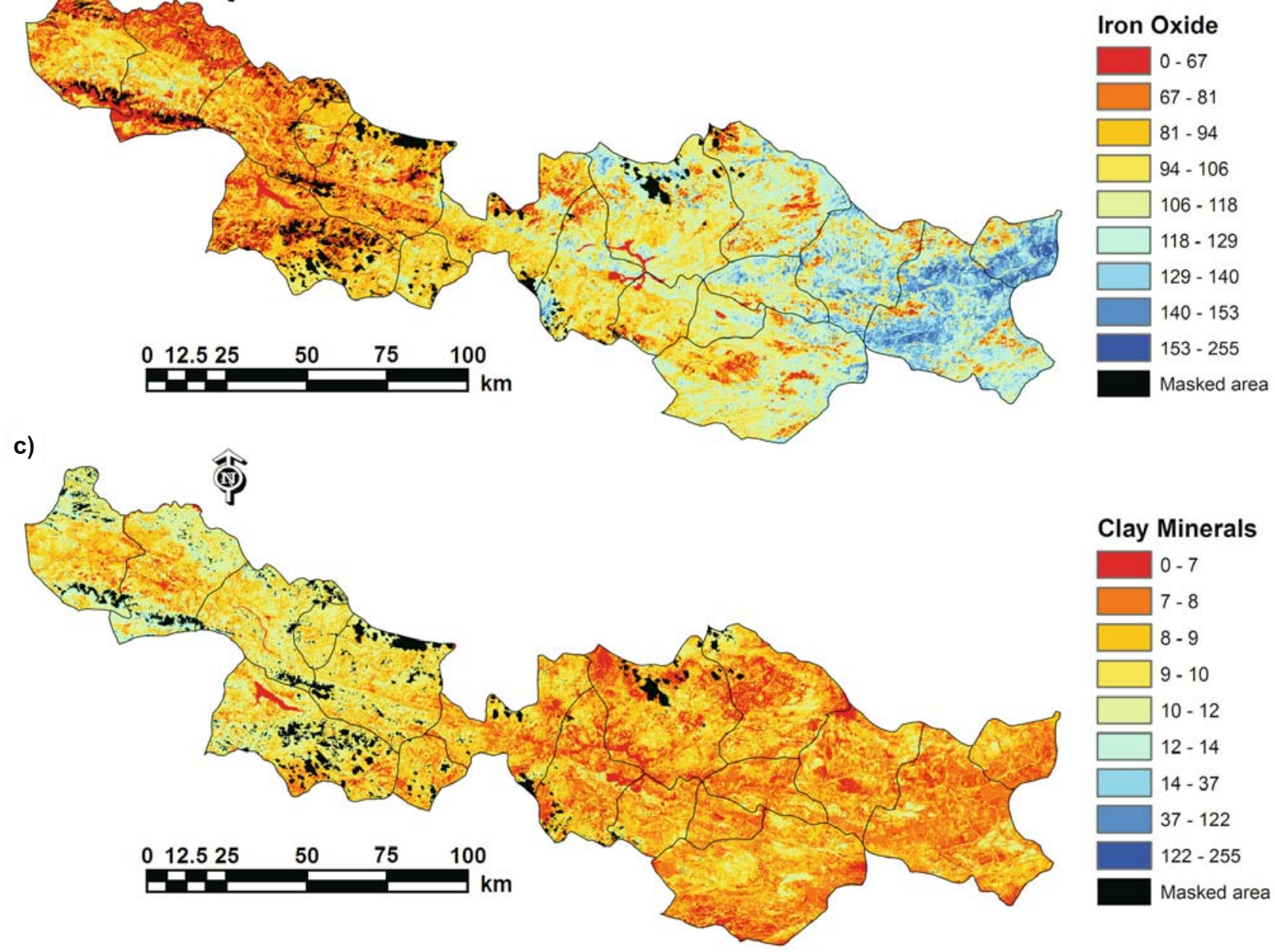

\section{Clay Minerals}

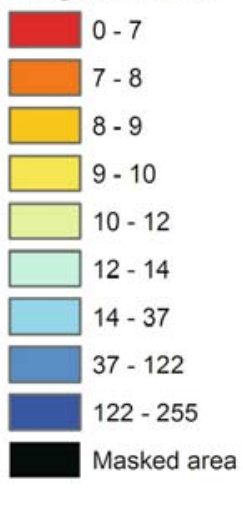

Figure 4. Ferrous minerals (a), iron oxide (b), and clay minerals (c) index maps of Kelkit Basin.

developed raster index maps were statistically filtered. Created MC index maps were reclassified in ARCGIS using 'natural breaks' method (figure 3) which are based on natural groupings inherent in the data and the features which are divided into classes whose boundaries are set where there are relatively big jumps in the data values (ESRI 2005). After reclassifying, all indices were summarized in nine classes which are easy to interpret (figure 4). 
Table 2. Class cover areas of ferrous minerals, iron oxide, and clay minerals in Kelkit Basin.

\begin{tabular}{|c|c|c|c|c|c|c|}
\hline \multirow[b]{2}{*}{ Class } & \multirow[b]{2}{*}{$\begin{array}{l}\text { Index } \\
\text { values }\end{array}$} & \multirow[b]{2}{*}{$\begin{array}{c}\text { Cover } \\
\text { area } \mathrm{km}^{2}\end{array}$} & \multirow[b]{2}{*}{$\begin{array}{c}\% \text { of the study } \\
\text { area }\end{array}$} & \multirow[b]{2}{*}{$\begin{array}{c}\% \text { of the total } \\
\text { district area }\end{array}$} & \multicolumn{2}{|c|}{ Interpretation } \\
\hline & & & & & Category & $\begin{array}{l}\% \text { of the total } \\
\text { district area }\end{array}$ \\
\hline \multicolumn{7}{|c|}{ Ferrous minerals } \\
\hline 1 & $0-12$ & 426.58 & 3.18 & 2.68 & & \multirow{6}{*}{74.22} \\
\hline 2 & $12-16$ & 1474.05 & 10.98 & 9.26 & \multirow{5}{*}{ Very rare } & \\
\hline 3 & $16-20$ & 2631.84 & 19.60 & 16.54 & & \\
\hline 4 & $20-24$ & 2983.39 & 22.22 & 18.75 & & \\
\hline 5 & $24-28$ & 2298.24 & 17.12 & 14.44 & & \\
\hline 6 & $28-32$ & 1996.40 & 14.87 & 12.55 & & \\
\hline 7 & $32-60$ & 1203.05 & 8.96 & 7.56 & Very rare- rare & 7.56 \\
\hline 8 & $60-143$ & 365.45 & 2.72 & 2.30 & Rare-medium & 2.30 \\
\hline 9 & $143-255$ & 46.50 & 0.35 & 0.29 & High-very high & 0.29 \\
\hline Total & & 13425.50 & 100.00 & 84.37 & & 84.37 \\
\hline \multicolumn{7}{|c|}{ Iron oxide } \\
\hline 1 & $0-67$ & 601.69 & 4.48 & 3.78 & Very rare-rare & 3.78 \\
\hline 2 & $67-81$ & 1136.95 & 8.47 & 7.15 & & \\
\hline 3 & $81-94$ & 1745.40 & 13.00 & 10.97 & Rare & 18.12 \\
\hline 4 & $94-106$ & 2440.72 & 18.18 & 15.34 & Rare-medium & 15.34 \\
\hline 5 & $106-118$ & 2663.85 & 19.84 & 16.74 & \multirow{4}{*}{ Medium } & \multirow{4}{*}{45.96} \\
\hline 6 & $118-129$ & 2331.50 & 17.37 & 14.65 & & \\
\hline 7 & $129-140$ & 1583.36 & 11.79 & 9.95 & & \\
\hline 8 & $140-153$ & 735.20 & 5.48 & 4.62 & & \\
\hline 9 & $153-255$ & 186.83 & 1.39 & 1.17 & High-very high & 1.17 \\
\hline Total & & 13425.50 & 100.00 & 84.37 & & 84.37 \\
\hline \multicolumn{7}{|c|}{ Clay minerals } \\
\hline 1 & $0-7$ & 158.34 & 1.18 & 1.00 & \multirow{7}{*}{ Very rare } & \multirow{7}{*}{84.15} \\
\hline 2 & $7-8$ & 1692.45 & 12.61 & 10.64 & & \\
\hline 3 & $8-9$ & 3900.36 & 29.05 & 24.51 & & \\
\hline 4 & $9-10$ & 3521.62 & 26.23 & 22.13 & & \\
\hline 5 & $10-12$ & 2327.87 & 17.34 & 14.63 & & \\
\hline 6 & $12-14$ & 1269.38 & 9.45 & 7.98 & & \\
\hline 7 & $14-37$ & 519.10 & 3.87 & 3.26 & & \\
\hline 8 & $37-122$ & 35.78 & 0.27 & 0.22 & Very rare-rare-medium & 0.22 \\
\hline 9 & $122-255$ & 0.60 & 0.00 & 0.00 & Medium-high-very high & 0.00 \\
\hline Total & & 13425.50 & 100.00 & 84.37 & & 84.37 \\
\hline
\end{tabular}

To research relationships among index maps, total 4138 points that cover the study area were set by $2 \times 2 \mathrm{~km}$ grid size on the index maps. Then, the points in the masking areas were eliminated. Consequently, 3754 points were determined to extract corresponding index values in ARCGIS. Organizing extracted values as an XYZ file in Microsoft Excel software (Microsoft 2003), bi-variety correlation analysis (Pearson coefficients) was conducted in SPSS 11 statistical software (SPSS 2001). MC raster maps were also interpreted at administrative district level.

All developed MC index maps were tested by using the ground truth data collected between 2006 and 2007. For this aim, soil analysis results (clay \%, and available $\mathrm{Fe}^{+2} \mathrm{Fe}^{+3} \mathrm{ppm}$ ) of 56 ground control points were evaluated. Relationships between field data and corresponding $\mathrm{MC}$ values derived from raster maps were investigated by applying correlation analysis (Pearson coefficients) in SPSS.

\section{Results}

Spatial distribution of FM, IO, and CM classes were determined and given in figure 4(A), (B) and $(\mathrm{C})$. Nine index classes were interpreted under five categories namely; very rare $(0-51)$, rare 

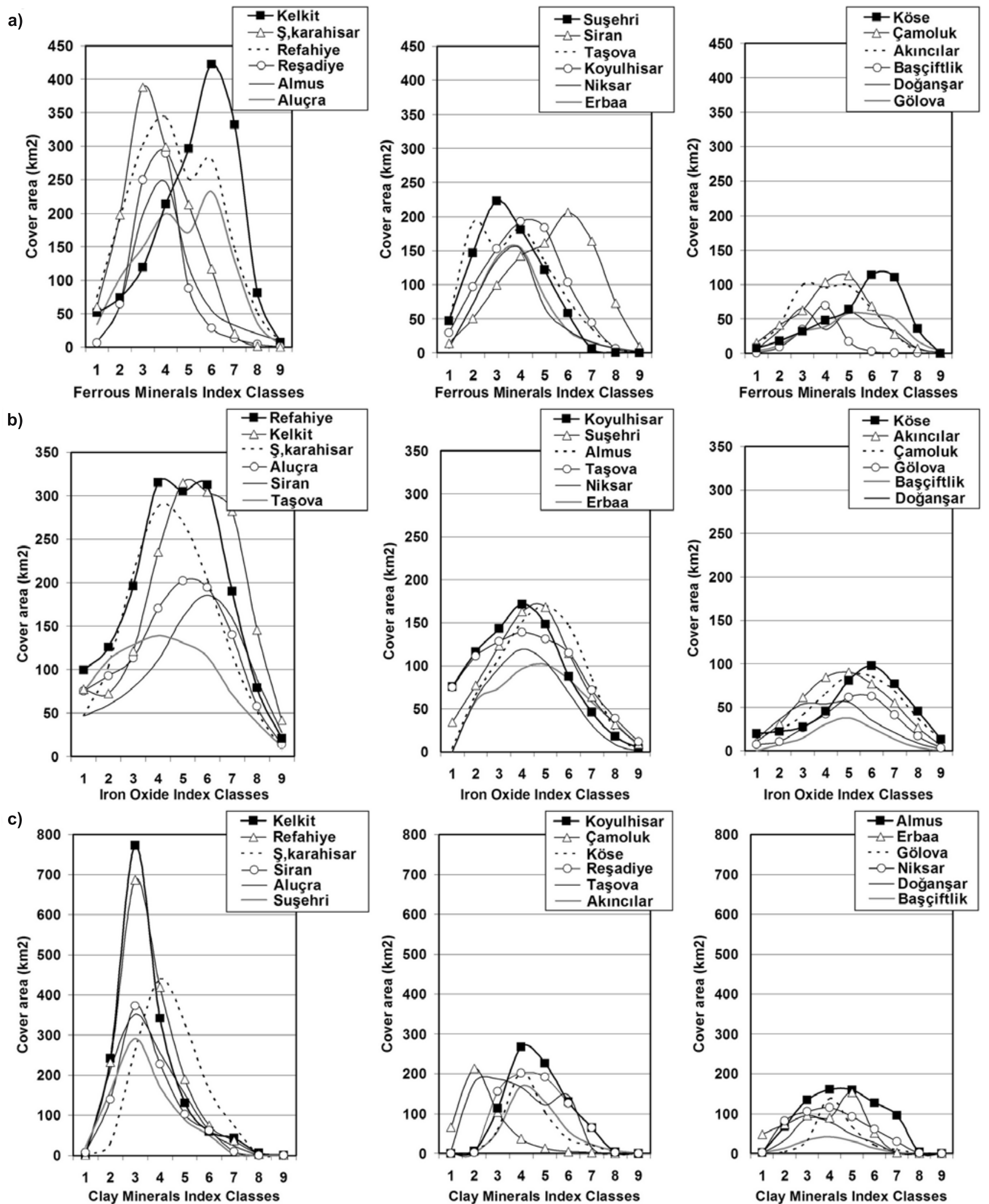

Figure 5. Mineral composite class covers in administrative districts of Kelkit Basin: ferrous minerals (a), iron oxide (b) and clay minerals (c).

(51-102), medium (102-153), high (153-204) and very high (204-255). According to the spatial distribution of FM, the main part of the study area
$(74.22 \%)$ was assessed in 'very rare' category, while the areas between 'very rare' and 'medium' categories covered small portion $(9.86 \%)$ of the total 
study area (table 2). The areas that contain FM in 'high-very high' category covered minor portion $(0.29 \%)$ of the study area. Spatial distribution of IO showed that nearly half of the province area $(45.96 \%)$ participated in 'medium' category, and this was ensued by 'rare' (18.12\%), 'rare-medium' $(15.34 \%)$, 'very rare-rare' $(3.78 \%)$, and 'high-very high' $(1.17 \%)$ categories, respectively. In CM point of view, the majority (84.15\%) of the study area was evaluated in 'very rare' category. The areas between 'very rare' and 'medium' categories covered very small part $(0.22 \%)$ of the study area, and no area was detected for 'medium-high-very high' categories (table 2).

At administrative district level, FM results (figure 5A) indicated that Kelkit, Şebinkarahisar, Refahiye, Reşadiye, Almus, and Aluçra districts established the first group where the largest areas were determined for the FM classes between 3 and 6. Areas within these classes participated in the 'very rare' category (table 2) and covered a total of $9909.87 \mathrm{~km}^{2}$ area in those districts. IO results (figure 5B) showed that Refahiye, Kelkit, Şebinkarahisar, Aluçra, Siran and Taşova have the largest areas where the IO classes between 4 and 6 were found. These IO classes were in 'rare-medium' and 'medium' categories (table 2), and contained a total of $7436.07 \mathrm{~km}^{2}$ area. CM results (figure 5C) delineated that Kelkit, Refahiye, Şebinkarahisar, Siran, Aluçra, and Suşehri have the largest areas where the CM classes between 3 and 4 were detected. These two classes were categorized as

Table 3. Pearson correlations of ferrous minerals $(F M)$, iron oxide (IO), and clay minerals (CM) indices.

\begin{tabular}{llll}
\hline Index & \multicolumn{1}{c}{ CM } & \multicolumn{1}{c}{ FM } & IO \\
\hline CM & 1 & & \\
FM & $-0.530(* *)$ & 1 & \\
IO & $-0.654(* *)$ & $0.751(* *)$ & 1 \\
\hline
\end{tabular}

** Correlation is significant at the 0.01 level (2-tailed). $N=3754$. 'very rare' (table 2), and covers $7124.98 \mathrm{~km}^{2}$ area in those districts.

Correlation analysis results of 3754 points delineated the relationships among produced raster maps (table 3). A positive correlation (0.751) was detected between FM and $\mathrm{IO}$ variables, while $\mathrm{CM}$ variable negatively correlated with FM $(-0.530)$ and IO $(-0.654)$ at $1 \%$ level.

Correlation analysis results between produced maps and ground truth data (testing database of 56 ground control points) indicated similar relationships (table 4). In this case, FM and IO variables showed positive correlation (0.779), while CM variable negatively correlated with FM $(-0.657)$ and IO $(-0.732)$ at $1 \%$ level. Moreover, some significant correlations between produced MC indices and ground truth data were detected at $1 \%$ level emphasizing the strong relationships between the computed values of indices and the observed values. CM variable, for instance, positively correlated (0.817) with percent clay amounts, while FM (0.862) and IO (0.754) variables positively correlated with available $\mathrm{Fe}^{+2} \mathrm{Fe}^{+3}$ (ppm) amounts (table 4). IO variable negatively correlated $(-0.585)$ with clay amounts indicating that clay minerals in this region have little or no iron content. Correlation analysis results of field data showed parallelism with the correlation analysis results of 3754 points, and confirmed the reliability of developed MC raster maps (table 4).

\section{Discussion and conclusions}

In this study, mineral composite raster maps of the Kelkit Basin were produced by using the RS and GIS tools. Consequently, the areas in rich and poor mineral composite content were determined with their cover size and geographical locations in a reliable and quicker way.

The overall results indicated that a considerable amount of area has moderate iron oxide but poor ferrous and clay minerals contents. Negative

Table 4. Relationships between mineral composite (FM: ferrous minerals, IO: iron oxide, CM: clay minerals) maps and ground truth data (clay\%, and available $\mathrm{Fe}^{+2} \mathrm{Fe}^{+3}$ ).

\begin{tabular}{|c|c|c|c|c|c|}
\hline \multirow[b]{2}{*}{ Index } & \multicolumn{3}{|c|}{ Mineral composite maps } & \multicolumn{2}{|c|}{ Ground truth data } \\
\hline & $\mathrm{CM}$ & FM & IO & Clay\% & $\begin{array}{c}\mathrm{Fe}^{+2} \mathrm{Fe}^{+3} \\
(\mathrm{ppm})\end{array}$ \\
\hline $\mathrm{CM}$ & 1 & & & & \\
\hline FM & $-0.657(* *)$ & 1 & & & \\
\hline IO & $-0.732(* *)$ & $0.779(* *)$ & 1 & & \\
\hline CLAY\% & $0.817(* *)$ & $-0.656(* *)$ & $-0.585(* *)$ & 1 & \\
\hline $\mathrm{Fe}^{+2} \mathrm{Fe}^{+3}(\mathrm{ppm})$ & $-0.608(* *)$ & $0.862(* *)$ & $0.754(* *)$ & $-0.584(* *)$ & 1 \\
\hline
\end{tabular}

** Correlation is significant at the 0.01 level (2-tailed). $N=56$. 
correlations between iron (FM, IO, $\mathrm{Fe}^{+2} \mathrm{Fe}^{+3}$ ) and clay (CM, Clay\%) variables suggested that the dominant clay minerals of the study area have low or no iron content. Consequently, the relationships among MC maps indicated that the prevalent type of clay minerals might possibly be smectite, illite, kaolinite, or chlorite in the study area. These outcomes were supported by several literature. For instance, in semiarid regions, when the iron content diminished, clay minerals such as montmorillonite, kaolinite and illite could be dominant in colloidal fractions. According to Borchardt (1977), formation from the group 2:1 type of smectite minerals could be supposed after the addition of little iron. Moreover, Yalcin and Gumuser (2000) reported that clay fraction is dominated by smectite and lesser amounts of I-S, illite, chlorite and kaolinite in Kelkit Valley. Finally, Kılıç (1987) reported the similar consequences in two soil profile that represent reddish chestnut soils in the lower Kelkit Basin (Tokat province).

Emphasizing the importance of LANDSATETM+ images, the correlation results of ground truth data proved the reliability of developed raster mineral composite maps. Although, LANDSAT$\mathrm{ETM}+$ images have moderate spatial resolution, they have the ability to develop reliable mineral composite maps of large areas. Moreover, easy access and low project cost characteristics make LANDSAT-ETM+ images more advantageous. Produced raster maps established a good digital database that can be used and further developed for the Kelkit Basin.

\section{Acknowledgements}

The author thanks the Michigan State University for sharing their satellite image archive with researchers in the web, and Professor Mustafa Kılıç, from Gaziosmanpaşa University Soil Department due to his valuable interpretations about clay minerals.

\section{References}

Akalan I 1977 Toprak Olusu, Yapısı ve Ozellikleri (Ankara, TR: Ankara Universitesi, Ziraat Fakultesi Yayinları 662/204) pp. 342.

Akhavi M S, Webster T L and Raymond D A 2001 RADARSAT-1 imagery and GIS modeling for mineral exploration in Nova Scotia, Canada; Geocarto International 16 55-61.

Akman Y and Daget Ph 1971 Quelques aspects synoptiques des climats de la Turquie; Extrait du Bulletin de la Société Languedocienne de Géographie 5/3 269-300.

Akman Y 1999 Iklim ve Biyoiklim, Biyoiklim Metodlari ve Turkiye Iklimleri (Ankara, Palme Press) pp. 350.
Atalay I 2006 Toprak Olusumu, Siniflandirilmast ve Cografyasi, 3. Baski (Ankara, TR: T.C. Cevre ve Orman Bakanligi, Agaclandirma ve Erozyon Kontrolu Genel Mudurlugu) pp. 584.

Bolt G H and Bruggenwert M G M 1976 Composition of the soil; In: Soil Chemistry A. Basic Elements (eds) Bolt G H and Bruggenwert M G M (Amsterdam, NL: Elsevier) pp. 1-3.

Borchardt G A 1977 Montmorillonite and other smectite minerals; In: Minerals in Soil Environment (eds) Dixon J B and Weed S B (Soil Science Society of America) pp. 293-330.

Brown J C 1956 Iron chlorosis; Annual Review of Plant Physiology 7 171-189.

Campbell J B 1996 Introduction to Remote Sensing, 2nd edn. (New York-London: The Guilford Press) pp. 468.

CDC 1998 Recommendations to prevent and control iron deficiency in the United States (Morbidity and Mortality Weekly Report (MMWR), US Department of Health and Human Services, Centers for Disease Control and Prevention (CDC), Atlanta, Georgia).

Durak A, Topbaş M T and Kilic K 2003 Mineraloji ve Petrografi (Tokat, TR: Gaziosmanpasa Universitesi, Ziraat Fakultesi 9/6) pp. 149.

Ellis R J and Scott P W 2004 Evaluation of hyperspectral remote sensing as a means of environmental monitoring in the St. Austell China clay (kaolin) region, Cornwall, UK; Remote Sensing of Environment $\mathbf{9 3}$ $118-130$.

ERDAS 2003 Erdas Field Guide, 7th edn. (Atlanta Georgia: Leica Geosystems, GIS and Mapping LLC) pp. 672.

ESRI 2004 ArcGIS 9, Geoprocessing in ArcGIS (Redlands, California: Environmental Systems Research Institute) pp. 363.

ESRI 2005 ArcGIS 9, What is in ArcGIS 9.1. (Environmental Systems Research Institute, Redlands, California, USA) pp. 123.

Farrand W H 1997 Identification and mapping of ferric oxide and oxyhydroxide minerals in imaging spectrometer data of Summitville, Colorado, USA, and the surrounding San Juan Mountains; Int. J. Remote Sensing 10 1543-1552.

Grim R E 1962 Applied Clay Mineralogy (New York, Toronto, London: McGraw-Hill) pp. 422.

Gris E 1844 Nouvelles experiences sur l'action des composes ferrugineux solubles, appliques a la vegetation, et specialement au traitement de la chlorose et de la debilite des plantes; Comptes Rendus de l Academie des Sciences (Paris) 19 1118-1119.

Haktanır K and Arcak S 1997 Toprak Biyolojisi, Toprak Ekosistemine Giris (Ankara, Turkey: Ankara Üniversitesi, Ziraat Fakültesi Yayınları, No: 1486/1447) pp. 409.

Jensen J R 1996 Introductory Digital Image Processing: A Remote Sensing Perspective, 2nd edn. (Englewood Cliffs, New Jersey: Prentice-Hall) pp. 316.

KHGM 2002 National soil database of Turkey; General Directorate of Rural Services of the Ministry of Agriculture and Rural Affairs in Turkey, Ankara. Available at online: http://www.khgm.gov.tr (accessed on 10 June 2006).

Kılıç M 1987 Tokat yoresindeki kirmizimsi topraklarin mikromorfogenesisi ve siniflandirilmasi; Cumhuriyet Universitesi, Tokat Ziraat Fakultesi Yayinlari, Bilimsel Arastırma ve Incelemeler 5/2 1-37.

Landsat.org. 2006 Global observatory for ecosystem services; Michigan State University, USA. Available at online: http://www.landsat.org/ortho/index.htm (accessed on 8 July 2006). 
Longhi I, Sgavetti M, Chiari R and Mazzoli C 2001 Spectral analysis and classification of metamorphic rocks from laboratory reflectance spectra in the $0.4-2.5 \mu \mathrm{m}$ interval: A tool for hyperspectral data integration; Int. J. Remote Sensing 22 3763-3782.

Microsoft 2003 Microsoft Office Excel. Microsoft Office Professional Edition (USA: Microsoft Corporation).

Moore D M and Reynolds R C Jr. 1997 X-Ray Diffraction and the Identification and Analysis of Clay Minerals (New York: Oxford University Press) pp. 378.

Murray H 2006 Applied Clay Mineralogy, Occurences, Processing and Application of Kaolins, Bentonites, Palygorskite-Sepiolite, and Common Clays (The Netherlands, Amsterdam: Elsevier Science) pp. 188.

Neville R A, Lévesque J, Staenz K, Nadeau C, Hauff P and Borstad G A 2003 Spectral unmixing of hyperspectral imagery for mineral exploration: Comparison of results from SFSI and AVIRIS; Canadian J. Remote Sensing $\mathbf{2 9}$ 99-110.

Pyroclay 2007 Amorphous silica clay; Heart Balance Herbal Rejuvenation, Ashland Oregon. Available at online: http://www.pyroclay.com/clay.htm (accessed on 24 April 2007).

Sabins F F Jr 1987 Remote Sensing Principles and Interpretation, 2nd edn. (New York: W. H. Freeman \& Co).
Sabol D E Jr, Bell J F III and Adams J B 1993 Detectability of crystalline ferric and ferrous minerals on Mars; In: Lunar and Planetary Inst. Twenty-Fourth Lunar and Planetary Science Conference, Part 3, 1229-1230.

Somers I I and Shive J W 1942 The iron and manganese relations in plant metabolism; Plant Physiology $\mathbf{1 7}$ 582-602.

Sposito G 1989 The Chemistry of Soils (New York and Oxford: Oxford University Press).

SPSS 2001 SPSS 11.0 for Windows. SPSS Inc., Chicago.

Tangestani M H and Moore F 2002 Porphyry copper alteration mapping at the Meiduk Area, Iran; Int. J. Remote Sensing 23 4815-4825.

Tucker C J 1979 Red and photographic infrared linear combinations for monitoring vegetation; Remote Sensing of Environment 8 127-150.

UNESCO 1973 International Classification and Mapping of Vegetation; Ecology and Conservation 6, UNESCO, Paris.

USGS 2006 LANDSAT Project; Available at online: http://landsat7.usgs.gov/index.php (accessed on 18 October 2006).

Yalcin H and Gumuser G 2000 Mineralogical and geochemical characteristics of late Cretaceous bentonite deposits of the Kelkit Valley Region, northern Turkey; Clay Minerals 35 807-825. 